patients who participated in this study. This project was supported by Bayer UK.

1 Beger HG, Bittner R, Block S, Buchler M. Bacterial contamination of pancreatic necrosis A prospective clinical study. Gastroenterology 1986;91: $433-8$

2 Frey CF, Bradley EL, Beger HG. Progress in acute pancreatitis. Surg Gynecol Obstet 1988;167:282-6.

3 Larvin M, Chalmers AG, Robinson PJ, McMahon MJ. Debridement and closed cavity irrigation for the treatment of pancreatic necrosis. $\mathrm{Br} f \mathrm{Sur}$ 1989;76:465-71

4 Bradley EL. Management of infected pancreatic necrosis by open drainage Ann Surg 1987;206:542-50.

5 Bittner R, Block S, Buchler M, Beger HG. Pancreatic abscess and infected pancreatic necrosis. Different local septic complications in acute pancreatitis. Dig Dis Sci 1987;32:1082-7.

6 Beger HG, Krautzberger W, Bittner R, Block S, Buchler M. Results of urgical treatment of necrotising pancreatitis. World F Surg 1985;9:972-9.

Corfield AP, Cooper MJ, Williamson RCN, et al. Prediction of severity in acute pancreatitis. Prospective comparison of three prognostic indices. acute pancreatitis.
Lancet $1985 ; \mathrm{ii}: 403-7$

8 Block S, Maier W, Bittner R, Buchler M, Malfertheiner P, Beger HG Identification of pancreas necrosis in severe acute pancreatitis: imaging procedures versus clinical staging. Gut 1986;27:1035-42.

9 Leese T, Shaw D, Holliday M. Prognostic markers in acute pancreatitis: can pancreatic necrosis be predicted? Ann R Coll Surg Engl 1988;70:227-32.

10 Swobodnick $W$. Controversies and limitations of ultrasonography in acute pancreatitis. In: Malfertheiner $\mathrm{P}$, Ditschuneit $\mathrm{H}$, eds. Diagnostic procedures in pancreatic disease. Berlin: Springer Verlag, 1985:32-6.

11 Nordback I, Pessi T, Auvinen O, Autio V. Determination of necrosis in necrotising pancreatitis. Br f Surg 1985;72:225-7.

12 Howard JM, Wagner SM. Pancreatography after recovery from massive pancreatic necrosis. Ann Surg 1989;209:31-5.

13 Ranson JHC, Balthazar E, Caccavale R, Cooper M. Computed tomography and the prediction of pancreatic abscess in acute pancreatitis. Ann Surg 1985;201:656-65.
4 Lawson TL. Acute pancreatitis and its complications. Computed tomography and sonography. Radiol Clin North Am 1983;21:495-513.

15 Schroder T, Kivisaari L, Somer K, Standertskjold-Nordenstam C-G, Kivilaakso $\mathrm{E}$, Lempinen $\mathrm{M}$. Significance of extrapancreatic findings in computed tomography of acute pancreatitis. Eur 7 Radiol 1985;5:273-5.

16 Nordestegaard AG, Wilson SE, Williams RA. Early computerised tomography as a predictor of outcome in acute pancreatitis. Am $\mathcal{J}$ Surg 1986;152:127-32.

17 Rotmann N, Bonnet F, Larde D, Fagniez P'-L. Computerised tomography in the evaluation of late complications of acute pancreatitis. Am $\mathcal{F}$ Surg 1986; 152:286-9.

18 Vernacchia FS, Jeffrey RB, Federle MP, et al. Pancreatic abscess: the predictive value of early CT. Radiology 1987;162:435-8

19 Lọndon NJ, Neoptolemos JP, Lavelle J, Bailey I, James D. Contrast enhanced computed tomography scanning and prediction of severity of acute pancreatitis: a prospective study. Brf Surg 1989;76:268-72.

20 Kivisaari L, Somer K, Standertskjold-Nordenstam C-G, Kivilaakso E, Lempinen $M$. A new method for the diagnosis of acute haemorrhagic necrotising pancreatitis using contrast enhanced CT scanning. Gastrointest Radiol 1984;9:27-30.

21 Knaus WA, Draper EA, Wagner DP, Zimmerman JE. APACHE-II: a severity of disease classification. Crit Care Med 1985:13:818-29.

22 Larvin M, McMahon MJ. APACHE-II score for assessment and monitoring of acute pancreatitis. Lancet 1989;ii:201-5.

23 Schroder T, Kivisaari L, Somer K, et al. The clinical significance of contrast enhanced computed tomography in acute pancreatitis. Ann Chir Gynaecol 1984;73:268-72.

24 Nuutinen P. Contrast enhanced computed tomography in acute oedematous pancreatitis. Surgical Research Communications 1987;1:251-9.

25 Nuutinen P, Kivisaari L, Schroder T. Contrast enhanced computed tomography and microangiography of the pancreas in acute human hemorrhagic necrotising pancreatitis. Pancreas 1988; 3:53-60.

26 Gerzof SG, Banks PA, Robbins AH, et al. Early diagnosis of pancreatic infection by computed tomography guided aspiration. Gastroenterology $1987 ; 93: 1315-20$.

(Accepted 22 February 1990)
Department of

Biomedical Science,

University of Sheffield,

Sheffield S10 2TN

R A Graham, BSC, research assistant

The late A W Rogers, DSC, formerly professor

P Dockery, PHD, lecturer

Departments of Obstetrics and Gynaecology,

Biochemistry, and

Molecular Biology,

University of Manchester,

St Mary's Hospital,

Manchester M13 0JH

$M$ W Seif, PHD, clinical tutor

J D Aplin, PHD, lecturer

Department of Obstetrics and Gynaecology, University of Sheffield, Jessop Hospital for Women, Sheffield S3 7RE T C Li, PHD, clinical lecturer I D Cooke, FRCOG, professor

Correspondence to:

Dr J D Aplin, Department of Obstetrics and

Gynaecology, Research

Floor, St Mary's Hospital,

Manchester M13 0JH.

Br.Med F 1990;300:1428-31

\title{
An endometrial factor in unexplained infertility
}

\author{
R A Graham, M W Seif, J D Aplin, T C Li, I D Cooke, A W Rogers, P Dockery
}

\section{Abstract}

Objective-To study a group of women with unexplained infertility to see whether they have a defect that is intrinsic to the endometrium.

Design-Evaluation of the functional response of the endometrium by examining endometrial biopsy specimens using immunohistochemical methods in a group of women with unexplained infertility and in a control group of women with normal fertility.

Patients -27 Women with unexplained infertility (average age 33.2); median duration of infertility five years. A control group of $\mathbf{4 4}$ women with normal fertility (average age 33.8 ) who were requesting sterilisation or reversal of sterilisation.

Setting-Infertility clinic, Jessop Hospital for Women, Sheffield.

Intervention-Secretory phase endometrial biopsy specimens were taken, with informed consent, as an outpatient procedure.

Main outcome measures -Immunohistochemistry with monoclonal antibody D9B1, was used to assess the production and secretion of an oligosaccharide epitope produced by endometrial gland cells between two and seven days after the luteinising hormone surge. A reflected light measuring system was used to assess the amount of epitope within the gland cells, and in the gland lumen.

Results - In the control group of women, mean reflected light measurements at the cell base and cell apex peaked at three and five days after the luteinising hormone surge respectively, and in the gland lumen the epitope accumulated rapidly from three days, reaching a peak at seven days. In the women with infertility the peaks of epitope at the cell base and cell apex were lower, broader, and delayed in onset, and the build up of epitope in the gland lumen was retarded. The synthesis and secretion of the epitope in the women with infertility was therefore significantly reduced and delayed, even in the presence of normal concentrations of circulating progesterone.

Conclusions-The results suggest that a primary dysfunction of the endometrium might be associated with hitherto unexplained infertility.

\section{Introduction}

Substantial numbers of patients with unexplained infertility attend infertility clinics, with reported prevalences ranging from $6 \%$ to almost $60 \%$. $^{1}$ The hormonal profiles of women with unexplained infertility have been much studied and are often normal, but in contrast, the endometrium has been comparatively unexplored as a factor in infertility. This has been justified by the widespread belief that endometrial morphology provides no more than a simple and faithful reflection of the ovarian cycle. The use of the endometrial biopsy specimen as an index of ovulation has been largely superseded by non-invasive, quantitative, sensitive, endocrine assays, and failure of the endometrium to respond fully to a normal ovarian stimulus has remained hypothetical.

The secretory differentiation of the endometrial epithelium has been characterised by raising monoclonal antibodies to hormonally regulated cell surface and secretory components. ${ }^{34}$ The monoclonal antibody D9B1 binds to a peptide associated sialooligosaccharide of the sulphated lactosaminoglycan family, ${ }^{56}$ which is secreted by gland cells mainly between three and seven days after the luteinising hormone surge. ${ }^{4}$ Study of the defective luteal phase has shown that there is a strong correlation between infertility and reduced production of the D9B1 epitope'; this deficiency may occur against a background of normal secretory differentiation as assessed by conventional histology. On the basis of these and 
other observations,${ }^{8}$ it has been suggested that there might be a group of women with infertility in whom the defect is intrinsic to the endometrium.?

To test this hypothesis we needed a well documented study group that included a control group of women with normal fertility. We have shown that if normal women of known fertility have endometrial biopsy specimens taken at a time that has been calculated prospectively from the luteinising hormone surge then the structure of the endometrium from two to seven days after this surge varies little between subjects, thus suggesting tight biological control.9 This approach eliminates errors arising from variations in the length of the luteal phase in the normal population. ${ }^{10}$ In our study we examined secretory phase biopsy specimens that had been taken from a group of 27 women with unexplained infertility and from 44 women with normal fertility, and compared the results from the two groups.

\section{Subjects and methods}

Endometrial biopsies were performed as an outpatient procedure on $\mathbf{4 4}$ women with normal fertility who were requesting sterilisation or the reversal of sterilisation and on 27 women with unexplained infertility. All had given their informed consent and all were attending the infertility clinic at the Jessop Hospital, Sheffield. The following criteria were used to assess fertility: regular menstrual cycles of 25-35 days, no history of menstrual disorders, previous achievement of a successful pregnancy, no history of infertility, and a normal luteinising hormone peak in the cycle in which the endometrial biopsy was performed. Subjects were excluded if they had taken steroid hormones (including the contraceptive pill) or had used an

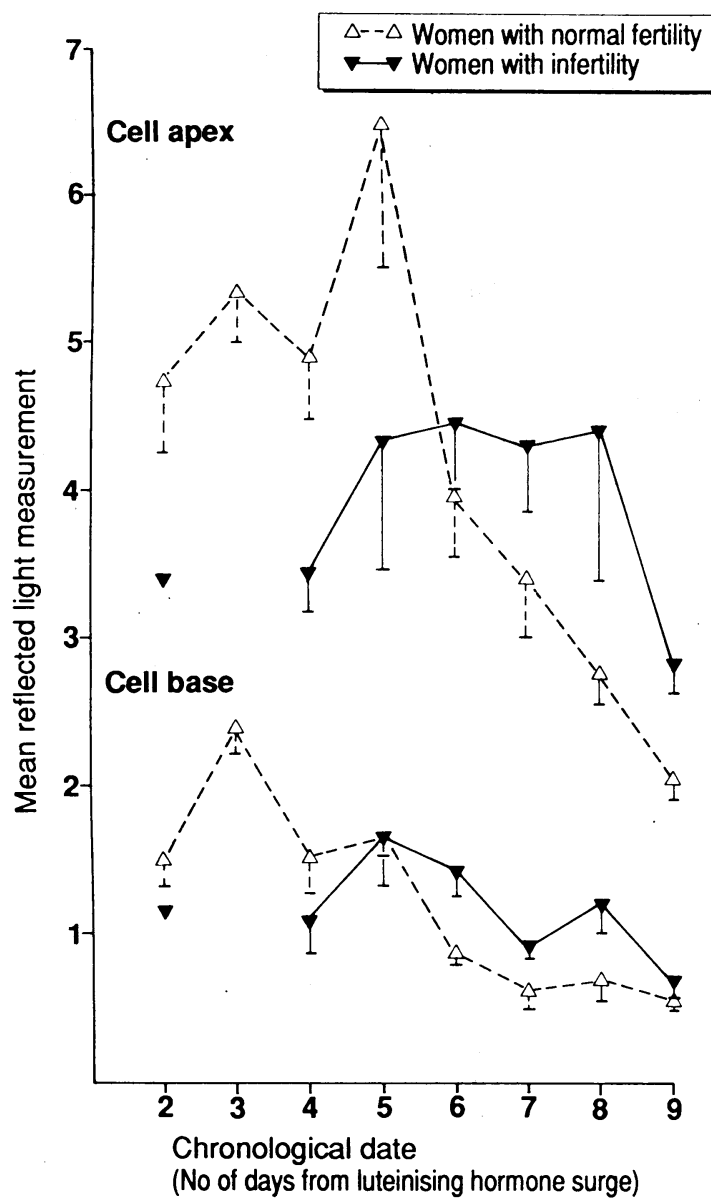

FIG 1-Mean reflected light measurements for cell base and cell apex of glandular epithelial cells on different days of luteal phase in women with normal fertility and in women with unexplained infertility. Bars at each point represent standard errors

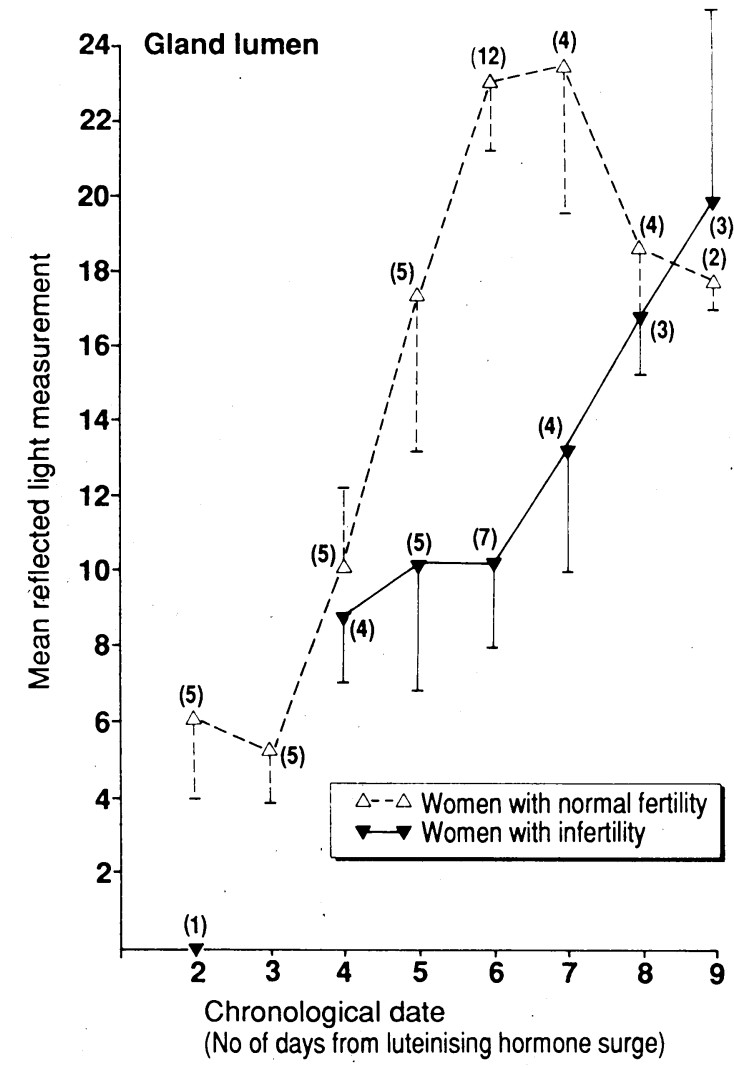

FIG 2-Mean reflected light measurements for gland lumen in women with normal fertility and in women with infertility on different days of luteal phase. Numbers in brackets at each point are numbers of subjects, and bars represent standard errors. Two of the 44 normal biopsies were in the proliferative phase, and are not shown.

intrauterine device in the three months before the study.

Infertility was referred to as unexplained if a cause could not be identified after completion of our routine fertility survey as defined by the following criteria: infertility of more than one year's duration, normal regular sexual intercourse, no ejaculatory problems, normal semen analysis as defined by the World Health Organisation, " normal regular menstrual cycles of 25 35 days, evidence of ovulation as detected by thermal and endocrinological criteria, normal thyroid function tests, normal plasma prolactin concentrations, and normal laparoscopic findings.

The biopsy specimens were all dated from the luteinising hormone surge, and were taken between two and nine days after this surge. Luteinising hormone and progesterone concentrations were measured by immunoassay. ${ }^{12}$

All the biopsy specimens were fixed and embedded in the resin JB4, ${ }^{9}$ and sections were stained by an indirect immunoperoxidase method using the monoclonal antibody D9B $1 .{ }^{3+}$ Tissue sections from reference blocks of normal endometrium were processed with each experimental section to serve as controls. The amount of antigen was determined by the ability of the product produced by the immunoperoxidase reaction to reflect light when viewed by incident illumination. ${ }^{413}$

Two blocks were prepared from specimens taken from each subject and 25 glands were examined on sections from each block. Semiquantitative measurements were taken from the base of each cell, and from the apex of each cell, and from the adjacent gland lumen. Background measurements were taken from nearby stromal tissue, which was unstained, and were subtracted from the experimental values. The resulting values were accumulated for each of the three sites measured in each individual subject. This method allowed direct comparisons of the amounts of immunodeposit between subjects at any one site to be made. 
Comparisons between the cell base and other sites might not have been accurate because the deposit might be in a different physical state at the cell

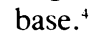

Data were analysed using Student's $t$ test and two way analysis of variance.

\section{Results}

The average age of the 44 women with normal fertility was 33.8 years (range 24-39). The average age of the 27 women with unexplained infertility was $33 \cdot 2$ (range 24-40). The median duration of their infertility was five years (range 2-10). Of these patients 19 had primary infertility and eight had secondary infertility. The number of subjects from whom biopsy specimens were taken for each day after the luteinising hormone surge is shown in figure 2 .

Figure 1 shows the mean reflected light measurements at the cell base and the cell apex for the two groups of subjects. In the women with normal fertility measurements at the cell base reached a peak three days after the luteinising hormone surge and measurements at the cell apex peaked at five days. Both values declined thereafter. This was consistent with accumulation of D9B1 epitope in the subnuclear area and its subsequent translocation to the cell apex before secretion. In the gland lumen epitope accumulated rapidly from three days after the luteinising hormone surge to reach a peak at seven days (fig 2). In contrast, in the group of women with infertility peaks of epitope concentration at the cell base and the cell apex were lower, broader, and delayed in onset, and the build up of epitope in the gland lumen was retarded by two days. In the infertile women the values for the cell apex four days after the luteinising hormone surge were significantly lower than those in the women with normal fertility $(t=2 \cdot 68, \mathrm{df}=7, \mathrm{p}<0 \cdot 025)$, and, similarly, the values for the gland lumen six days after the luteinising hormone surge were also significantly lower $(t=4.45, \mathrm{df}=17, \mathrm{p}<0.005)$. The measurements at the cell base six days after the luteinising hormone surge were significantly higher in the infertile women than in the group with normal fertility $(t=3 \cdot 25, \mathrm{df}=17$, $\mathrm{p}<0.005)$ thus suggesting a delay in the temporal progression of the epitope to its discharge into the gland lumen in women with infertility.

Table I shows the results of a two way analysis of

TABLE I-Two way analysis of variance performed on data from women with normal fertility and women with infertility

\begin{tabular}{|c|c|c|c|}
\hline & \multicolumn{3}{|c|}{ Source of variation } \\
\hline & $\begin{array}{l}\text { Fertile or infertile } \\
\qquad(\mathrm{df}=1,57)\end{array}$ & $\begin{array}{l}\text { Chronological date of } \\
\text { biopsy specimen } \\
\text { from luteinising hormone surge } \\
(\mathrm{df}=5,57)\end{array}$ & $\begin{array}{c}\text { Interaction of } \\
\text { fertile or infertile } \\
\text { with date of specimen } \\
(\mathrm{df}=1,57)\end{array}$ \\
\hline \multicolumn{4}{|c|}{ Part of cell examined: } \\
\hline Base & $4.95^{\star}$ & $9 \cdot 17^{\star \star}$ & $2.55^{\star}$ \\
\hline Apex & 0.02 & $3 \cdot 70^{\star \star}$ & $2 \cdot 77^{\star}$ \\
\hline Lumen & $16 \cdot 65^{\star \star}$ & $3 \cdot 21^{\star}$ & 1.95 \\
\hline
\end{tabular}

TABLE II - Two way analysis of variance performed on data from women with normal fertility and from women with infertility who had normal profiles of progesterone

\begin{tabular}{lccc}
\hline & Source of variation & \\
\cline { 2 - 4 } & $\begin{array}{c}\text { Fertile or infertile } \\
(\mathrm{df}=1,38)\end{array}$ & $\begin{array}{c}\text { Chronological date of } \\
\text { biopsy specimen } \\
\text { from luteinising hormone surge } \\
(\mathrm{df}=5,38)\end{array}$ & $\begin{array}{c}\text { Interaction of } \\
\text { fertile or infertile } \\
\text { with date of specimen } \\
(\mathrm{df}=1,38)\end{array}$ \\
\hline $\begin{array}{l}\text { Part of cell examined: } \\
\text { Base }\end{array}$ & $9 \cdot 71^{\star \star}$ & $12 \cdot 32^{\star \star}$ & \\
$\begin{array}{l}\text { Apex } \\
\text { Lumen }\end{array}$ & $0 \cdot 01$ & $4 \cdot 75^{\star \star}$ & $2 \cdot 32+$ \\
\hline
\end{tabular}

$\mathrm{df}=$ degrees of freedom (numerator, denominator).

${ }^{\star} \mathrm{p}<0.05 ;{ }^{\star \star} \mathrm{p}<0.01 ; \mathrm{pp}=0.062$. variance that was performed on the data from the fertile and infertile women at four, five, six, seven, eight, and nine days after the luteinising hormone surge. The reflected light measurements of the basal region of the cell and of the gland lumen showed a significant effect of condition - that is, infertility compared with normal fertility. A significant effect of date (the chronological date of the biopsy specimen; expressed as days from the luteinising hormone surge) was seen in all three regions of the glands examined. In the cell base and apex a significant interaction between condition and date was found - that is, as the menstrual cycle progressed the differences became more pronounced.

Daily salivary progesterone concentrations from two to seven days after the luteinising hormone surge were available for 23 of the 27 women with infertility, and 18 of these had values for each day that were normal (defined as above the fifth percentile value for the group of 44 women with normal fertility). ${ }^{14}$ Three of them had some values that were below normal and the remaining two had values that were consistently lower than normal. Table II shows the results of a two way analysis of variance that was performed on data from the women with normal fertility and from those women with infertility who had normal concentrations of progesterone at four, five, six, seven, eight, and nine days after the luteinising hormone surge. Date and condition were found to have a highly significant effect on the reflected light measurements obtained from the cell base, but only date has a significant effect in the cell apex. The changes in the gland lumen again reflected the changes in the cell base, with the condition and date having significant effects. The $t$ values previously calculated retained their significance when testing was restricted to the 18 women with normal salivary progesterone concentrations. This analysis showed that the women with infertility who had normal concentrations of progesterone exhibited diminished amounts of the D9B1 epitope.

There was no significant difference in secretory activity between patients with primary infertility and those with secondary infertility.

\section{Discussion}

The development of a molecular probe for analysing endometrial secretory differentiation allows a new approach to be made to the characterisation of normal and defective endometrial function. ${ }^{347}$ Our results were consistent with reduced and delayed secretion of the D9B 1 epitope in infertility. Moreover, because the concentrations of circulating progesterone were normal in most of the women in this group the data provided evidence to show that the response of the endometrium to a normal ovarian stimulus had been retarded. The average ages of the women with normal fertility and of those with unexplained infertility were comparable and therefore age could be excluded as a factor that might have influenced secretory activity. Abnormality of $\mathrm{D} 9 \mathrm{~B} 1$ production occurred in women with primary infertility and in those with secondary infertility, and hence the difference in secretory behaviour that was seen between the women with normal fertility and the women with infertility did not seem to be due to a nonspecific effect of a previous pregnancy.

The function of the glycoprotein carrying the D9B 1 epitope is unknown. Its temporal distribution in the endometria of women with normal fertility has been shown to coincide with the peri-implantation period. ${ }^{4}$ Our data have shown that it provides a positive diagnostic feature in unexplained infertility, which hitherto has been dependent on the exclusion of all other known causes of infertility.

In summary, our results have shown an endometrial 
abnormality that is associated with unexplained infertility and which is not due to low concentrations of circulating progesterone.

This work was funded by a grant from Birthright.

1 Templeton AA, Penney GC. The incidence, characteristics, and prognosis of patients whose infertility is unexplained. Fertil Steril 1982;37:175-82.

2 Aplin JD, Seif MW. A monoclonal antibody to a cell surface determinant in human endometrial epithelium: stage-specific expression in the menstrua cycle. Am f Obstet Gynecol 1987;156:250-3.

3 Seif $\mathrm{MW}$, Aplin JD, Foden LJ, Tindall VR. A novel approach for monitoring the endometrial cycle and detecting ovulation. Am $\mathcal{F}$ Obstet Gynecol 1989;160:357-62

4 Smith RA, Seif MW, Rogers AW, et al. The endometrial cycle: the expression of a secretory component correlated with the luteinising hormone peak. Hum Reprod 1989:4:236-42.

5 Aplin JD, Hoadley ME, Seif MW. Hormonally regulated secretion of keratan sulphate by human endometrial epithelium. Biochem Soc Trans 1989;17. 136-7.

6 Hoadley ME, Aplin JD, Seif MW. Menstrual cycle-dependent expression of keratan sulphate in human endometrium. Biochem 7 1990;266:757-63.
7 Seif $\mathrm{MW}$, Aplin JD, Buckley CH. Luteal phase defect: the possibility of an immunohistochemical diagnosis. Fertil Steril 1989;51:273-9.

8 Seif $\mathrm{MW}$, Aplin JD, Awad H, Wells D. The effect of the intrauterine contraceptive device on endometrial secretory function: a possible mode of action. Contraception 1989;40:81-9.

9 Dockery P, Li TC, Rogers AW, Cooke ID, Lenton EA, Warren MA. An examination of the variation in timed endometrial biopsies. Hum Reprod 1988:3:715-20.

10 Li TC, Rogers AW, Lenton EA, Dockery P, Cooke ID. A comparison between two methods of chronological dating of human endometrial biopsies during the luteal phase, and their correlation with histologic dating. Fertil Steril 1987;48:928-32.

11 Belsey MA, Eliasson R, Gallegos AJ, Moghissi KS, Paulsen CA, Prased MRN Laboratory manual for the examination of semen andemen-cervical mucus interaction. Singapore: Press Concern, 1980

12 Lenton EA, Gelsthorpe CH, Harper R. Measurement of progesterone in saliva: assessment of the normal, fertile range using spontaneous conception cycles. Clin Endocrinol 1988;28:637-46.

13 Rogers AW. The microscopy and photography of autoradiographs. In Rogers $\mathrm{AW}$, ed. Techniques of autoradiography. 3rd ed. Amsterdam: Elsevier, 1979:148-64

14 Li TC, Lenton EA, Dockery P, Rogers AW, Cooke ID. The relation between daily salivary progesterone profile and endometrial development in the luteal phase of fertile and infertile women. Br F Obstet Gynaecol 1989;96:445-53.

(Accepted 30 March 1990)

\title{
Low back pain of mechanical origin: randomised comparison of chiropractic and hospital outpatient treatment
}

\author{
T W Meade, Sandra Dyer, Wendy Browne, Joy Townsend, A O Frank
}

Abstract

Objective-To compare chiropractic and hospital outpatient treatment for managing low back pain of mechanical origin.

Design-Randomised controlled trial. Allocation to chiropractic or hospital management by minimisation to establish groups for analysis of results according to initial referral clinic, length of current episode, history, and severity of back pain. Patients were followed up for up to two years.

Setting-Chiropractic and hospital outpatient clinics in 11 centres.

Patients-741 Patients aged 18-65 who had no contraindications to manipulation and who had not been treated within the past month.

Interventions - Treatment at the discretion of the chiropractors, who used chiropractic manipulation in most patients, or of the hospital staff, who most commonly used Maitland mobilisation or manipulation, or both.

Main outcome measures-Changes in the score on the Oswestry pain disability questionnaire and in the results of tests of straight leg raising and lumbar flexion.

Results-Chiropractic treatment was more effective than hospital outpatient management, mainly for patients with chronic or severe back pain. A benefit of about $7 \%$ points on the Oswestry scale was seen at two years. The benefit of chiropractic treatment became more evident throughout the follow up period. Secondary outcome measures also showed that chiropractic was more beneficial.

Conclusions-For patients with low back pain in whom manipulation is not contraindicated chiropractic almost certainly confers worthwhile, long term benefit in comparison with hospital outpatient management. The benefit is seen mainly in those with chronic or severe pain. Introducing chiropractic into NHS practice should be considered.

\section{Introduction}

The high incidence of back pain, its chronic and recurrent nature in many patients, and its contribution as a main cause of absence from work are well known. No general consensus exists about the most effective treatment. Largely anecdotally, patients and therapists often claim great improvements after manipulative treatment by alternative practitioners, including chiropractors. A recent report from the board of science and education of the BMA considered that manipulative treatment of back pain by lay practitioners may provide "a safe and helpful service," thus strengthening the Cochrane committee's recommendation that randomised trials of treatment for back pain should include an evaluation of heterodox methods."

A comparison of chiropractic with conventional hospital outpatient management of low back pain could take one of two main forms. Firstly, it could be a "pragmatic" trial, which would test what happens in day to day practice and in which details of the type, frequency, and duration of treatment would be at the discretion of the chiropractor or hospital team. ${ }^{3}$ The disadvantage of a pragmatic trial is that if a clear difference is found between the treatments it may not be possible to identify the components of the more successful treatment that were responsible. Secondly, it could be a "fastidious" trial, which would compare chiropractic manipulation with a particular form of non-manipulative physiotherapy. ${ }^{3}$ Though this type of trial may be more likely to identify specific components of treatment that are effective, there would be a high chance of not including the effective components because of the many techniques used to treat back pain. ${ }^{4}$ In addition, its results might have only limited applicability.

We adopted a pragmatic approach for two main reasons: firstly, because of the probable difficulty of securing agreement about standard forms of treatment, particularly in hospital, and consequently the smal number of patients who could be recruited into a fastidious trial and, secondly, because the effectiveness of treatment in day to day practice, whether chiropractic or in hospital, is of most immediate interest to patients as well as doctors and therapists.

\section{Patients and methods}

CENTRES AND CLINICS

The study was based on the methods of a feasibility study. ${ }^{5}$ Each centre consisted of a chiropractic clinic 